\title{
Revisión de los patrones ecográficos de los tumores testiculares germinales más frecuentes
}

\section{Review of the ultrasound patterns of the most frequent germ testicular}

\section{tumors}

Heber T. Alonso-Que*, Liah Castillo-Uribe y Aline Rivas-López

Servicio de Radiología e Imagen, Hospital Ángeles Clínica Londres, Ciudad de México, México

\section{RESUMEN}

El cáncer testicular es la neoplasia maligna más común en hombres de 20 a 35 años de edad, y representa del 1 al 2\% del total de los cánceres en el hombre. El diagnóstico temprano supone una tasa de curación cercana al 99\%. El 90 a 95\% de las neoplasias testiculares se originan en las células germinales por células espermatogénicas, lo que la hace la neoplasia testicular de mayor importancia para su estudio y detección. Los tumores de células germinales se subdividen en dos grupos: seminomatosos y no seminomatosos. Esta distinción es importante para el tratamiento y el pronóstico. El ultrasonido es la modalidad de imagen de elección para la evaluación de la patología testicular.

Palabras clave: Neoplasia testicular. Tumor de células germinales. Ultrasonido. Doppler.

\section{ABSTRACT}

The testicular cancer is the most common malignancy in men 20 to 35 years of age, represents 1 to $2 \%$ of all cancers in men, early diagnosis has a cure rate close to $99 \%$. The 90 to $95 \%$ of the testicular neoplasms originate in the germinal cells by spermatogenic cells, which makes it the testicular neoplasm of greater importance for its study and detection. Germ cell tumors are subdivided into two groups: seminomatous and non-seminomatous. This distinction is important for treatment and prognosis. Ultrasound is the modality of image of choice for the evaluation of testicular pathology.

Key words: Testicular neoplasm. Germinal cell tumor. Ultrasound. Doppler. 


\section{INTRODUCCIÓN}

El cáncer testicular es la neoplasia maligna más común en hombres de 20 a 35 años de edad y representa del 1 al 2\% del total de los cánceres en el hombre. El diagnóstico temprano tiene una tasa de curación cercana al 99\%. El 90 al 95\% de las neoplasias testiculares se originan en las células germinales por células espermatogénicas, lo que la hace la neoplasia testicular de mayor importancia para su estudio y detección. Los tumores de células germinales se subdividen en dos grupos: seminomatosos y no seminomatosos. Esta distinción es importante para el tratamiento y el pronóstico ${ }^{1,2}$. Por ello, conocer los datos clínicos, los hallazgos ultrasonográficos y su correlación patológica nos permite buscar de forma intencionada la presentación de cada tipo y subtipo de los tumores de células germinales.

El desarrollo del ultrasonido (US) de multifrecuencia y de los transductores de banda ancha, con el uso de la escala de grises, las modalidades de Doppler color, Doppler power (angio-Doppler), Doppler pulsado y Doppler dúplex, han mejorado notablemente la capacidad diagnóstica y la calidad de las imágenes, particularmente en los tejidos superficiales.

En la exploración de los testículos, el US es la modalidad de imagen de elección para la evaluación de su patología. El US permite contestar dos de las preguntas más importantes sobre las lesiones: si son intratesticulares o extratesticulares, y si son sólidas o quísticas; además, permite valorar el involucro de las estructuras extratesticulares.

\section{ANTECEDENTES}

\section{Embriología}

Las gónadas aparecen inicialmente como un par de prominencias longitudinales, los pliegues o crestas genitales, que se forman por la proliferación del epitelio superficial (celómico) y la condensación del mesénquima. Las células germinales aparecen en los pliegues germinales a partir de la sexta semana del desarrollo, formando los cordones sexuales primitivos (gónadas indiferentes) por la influencia del gen SRY localizado en el cromosoma $Y$, que codifica al factor determinante testicular, y diferencia a los cordones primitivos por la proliferación en cordones testiculares, que están formados por células germinales primordiales y células sustentaculares de Sertoli.

Estos cordones se disgregan en una red que dará origen a los túbulos de la red de Haller o rete testis. Los cordones testiculares están separados del epitelio superficial por un tejido conectivo fibroso: la túnica albugínea. Las células de Leydig se desarrollan a partir del mesénquima original de la cresta gonadal y se encuentran entre los cordones testiculares; en la octava semana empiezan a producir testosterona para la diferenciación de los conductos genitales y los genitales externos.

Los embriones, tanto masculinos como femeninos, tienen inicialmente dos pares de conductos genitales: los conductos mesonéfricos (o de Wolff) y los conductos paramesonéfricos (o de Müller). Las células de Sertoli producen una sustancia inhibidora mülleriana que 
provoca la regresión de los productos paramesonéfricos (de Müller). La persistencia de los paramesonéfricos (de Wolff) formará los conductos deferentes, el epidídimo y los conductos eyaculadores.

A la octava semana de gestación inicia el proceso de evaginación y el peritoneo de la porción inferior de la cavidad abdominal desciende con una elongación formando la túnica vaginalis. Este proceso resulta en las capas que forman el escroto en el adulto. Se mantiene una comunicación directa entre esta envoltura y la cavidad peritoneal, que se oblitera a las pocas semanas del nacimiento. El descenso testicular se lleva a cabo por la guía del gubernaculum testis (cordón ligamentoso que se extienden desde el testículo hasta la bolsa escrotal o músculo dartos de la bolsa escrotal $)^{3}$.

\section{Características anatómicas}

El testículo adulto normal es ovoide, mide $3 \mathrm{~cm}$ en su diámetro anteroposterior, 2 a 4 $\mathrm{cm}$ de ancho y 3 a $5 \mathrm{~cm}$ de longitud. Cada testículo pesa en promedio de 12.5 a $19 \mathrm{~g}$, y disminuye de tamaño y peso con la edad. Por US presenta una ecogenicidad granular homogénea, rodeado por una cápsula fibrosa blanca, la túnica albugínea, que se invagina en la porción posterior para formar el mediastino testicular. Los túbulos rectos entran en el mediastino formando una red de conductos dentro del estroma testicular, llamado rete testis.

El epidídimo está localizado posterolateral al testículo, en el adulto mide 6-7 cm de longitud y está compuesto de cabeza, cuerpo y cola. La cabeza (también conocida como globus mayor) mide 10 a $12 \mathrm{~mm}$ de diámetro y es ligeramente de mayor ecogenicidad. El cuerpo o corpus mide menos de $4 \mathrm{~mm}$ de diámetro y es isoecogénico o hipoecogénico (el conducto que forma el cuerpo puede medir 600 $\mathrm{cm}$ de longitud). La cola o globus menor puede medir de 2 a $5 \mathrm{~mm}$ y está unida de forma laxa al polo inferior del testículo.

Existen cuatro apéndices testiculares: el apéndice testicular (Morgani), el apéndice epidídimo, de vasos aberrantes y los paraepidídimicos; estos son vestigios de los conductos paramesonéfricos y mesonéfricos.

El flujo sanguíneo testicular lo suministran de forma primaria las arterias deferenciales, cremastérica (espermática externa) y testicular. El cordón espermático está compuesto por el vaso deferente, las arterias cremastérica, la deferencial y testicular, un plexo pampiniforme de venas, linfáticos y los nervios de los testículos ${ }^{4}$.

\section{Técnica de exploración por ecografía}

El US es la modalidad de imagen de elección para la caracterización de las lesiones escrotales. Permite una excelente resolución espacial y se puede lograr una sensibilidad cercana del $100 \%$. Además, tiene la ventaja de su fácil disponibilidad, ausencia de radiación ionizante y bajo coste. Las condiciones patológicas intratesticulares frente a las extratesticulares pueden diferenciarse con una sensibilidad del 98 al 100\%.

La exploración se inicia en posición del paciente en supino dorsal. Se colocan toallas entre 
ambos muslos y por debajo del escroto, y se pide al paciente que retraiga el pene sin ocasionar tensión. Se aplica gel tibio y se coloca el transductor con la mínima presión sobre el escroto. Se utiliza un transductor lineal multifrecuencia (de 5 a $17 \mathrm{MHz}$ ), el cual permitirá una adecuada penetración de los tejidos. Se revisa en la modalidad en escala de grises y con Doppler color, en proyecciones longitudinal y transversal.

En nuestra institución seguimos una serie de protocolos estandarizados, iniciando la exploración del testículo con proyecciones longitudinales y transversales midiendo los diámetros mayores, aplicando Doppler color y escala de grises, y posteriormente revisamos las estructuras extratesticulares (epidídimo, cordón espermático y plexo pampiniforme).

\section{Neoplasias testiculares}

Las neoplasias testiculares representan del 1 al 2\% del total de los cánceres en el sexo masculino y son la neoplasia maligna más común en pacientes de 15 a 34 años de edad. Se estima que hay 7,200 nuevos casos por año en los EE.UU. En Europa, el riesgo de cáncer testicular es relativamente menor: entre el 0.5 y el $1 \%$. Entre los factores asociados a las neoplasias testiculares se encuentran un tumor testicular previo, criptorquidia, infertilidad, síndrome de sexo indiferenciado (disgénesis gonadal, pseudohermafroditismo $\mathrm{y}$ hermafroditismo) y microcalcificaciones. La mayoría de las masas extratesticulares son benignas y la mayoría de las masas intratesticulares son malignas ${ }^{5,6}$.

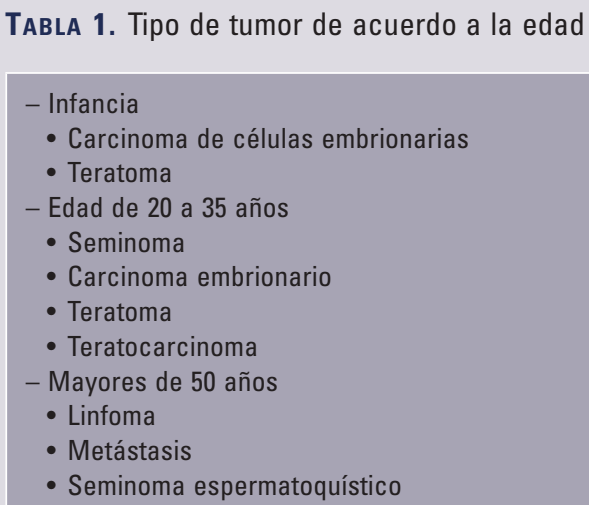

La prevalencia de los tumores va de acuerdo con la edad; se considera que hay dos picos de incidencia: de los 20 a los 35 años y en mayores de 50 años (Tabla 1). Los síntomas de cáncer testicular son endurecimiento, dolor leve y aumento de tamaño; cuando inicia con dolor, generalmente está asociado a hemorragia o infección. Un pequeño grupo pueden presentar tumores hormonales activos, con anormalidades endocrinas semejantes al síndrome de feminización?

Los tumores testiculares malignos están divididos en dos principales grupos: tumores de células germinales y tumores no de células germinales. Del 90 al 95\% de los tumores testiculares primarios se originan en las células germinales y tienen un alto potencial de malignidad, por lo que son el motivo de investigación en nuestro estudio. Únicamente el $60 \%$ de los tumores testiculares de células germinales tienen un solo tipo histológico, y el resto contiene dos o más tipos histológicos. Los tumores de células germinales son clasificados en seminomatosos (representan el 40 al $50 \%$ de los casos) y no seminomatosos (del 40 al 60\% de los casos). Esta distinción es importante para el tratamiento y el pronóstico. Los 
Tabla 2. Clasificación de las neoplasias testiculares

Tumores de células germinales
- Tumor de células germinales seminomatoso (seminoma)
- Clásico
- Espermatoquístico
- Anaplásico
- Tumor de células germinales no seminomatoso
- Carcinoma de células embrionarias
- Tumor del saco vitelino o tumor del seno endodérmico
- Teratoma (maduro o inmaduro)
- Coriocarcinoma
- Tumor de células germinales mixto
- Carcinoma de células embrionarias más teratoma (teratocarcinoma)
- Coriocarcinoma y otros tipos de células
Tumores del estroma
- Tumor de las células de Leydig
- Tumor de las células de Sertoli
- Gonadoblastoma
- Tumor de las células granulosas
- Tumor de las células tecas
- Linfoma, leucemia, metástasis y lesiones semejantes a tumores
Adaptada de Kocakoc, et al.7

tumores gonadales estromales se originan de las células de Sertoli (cordones sexuales) o de las células de Leydig (estroma), representan del 3 al 6\% del total de las masas testiculares, la mayoría de estas neoplasias mesenquimatosas son benignas y solo el $10 \%$ son malignas (Tabla 2).

El linfoma es en promedio el 5\% de los tumores testiculares, y más comúnmente es bilateral y en personas mayores de 50 años. La leucemia primaria del testículo es rara, pero la infiltración leucémica del testículo durante la remisión de la médula ósea es común en los niños; actúa como un reservorio para las células leucémicas durante la quimioterapia, a causa del paso de células por la barrera gonadal/sanguínea. La frecuencia más alta se encuentra en pacientes con leucemia aguda, hasta un 64\%. Las metástasis testiculares son raras (la incidencia es del $0.68 \%$ ); los
Tabla 3. Paciente con metástasis

\begin{tabular}{|l|l|}
\hline Metástasis a distancia & $\begin{array}{l}\text { Ganglios retroperitoneales } \\
\text { Ganglios mediastinales } \\
\text { Ganglios del cuello } \\
\text { Hígado } \\
\text { Pulmón }\end{array}$ \\
\hline $\begin{array}{l}\text { Estudios de extensión por } \\
\text { imagen para estadificación }\end{array}$ & $\begin{array}{l}\text { Ultrasonido } \\
\text { Tomografía } \\
\text { Tomografía computarizada por } \\
\text { emisión de positrones } \\
\text { Resonancia magnética }\end{array}$ \\
\hline Marcadores serológicos & $\begin{array}{l}\text { Alfa-fetoproteína } \\
\text { Subunidad beta de la hormona } \\
\text { gonadotropina coriónica humana }\end{array}$ \\
\hline
\end{tabular}

tumores primarios más comunes que producen metástasis al testículo son los de próstata $(35 \%)$, pulmón $(19 \%)$, melanoma $(9 \%)$, colon (9\%) y riñón $(7 \%)$.

Las metástasis de los tumores de células germinales pueden diseminarse por dos rutas principales, la hematógena y la linfática, con excepción del coriocarcinoma, que solo lo hace por vía hematógena; la extensión directa a través de la túnica albugínea hacia la piel del escroto es un hallazgo raro y tardío. El drenaje linfático testicular es importante para entender la extensión. La cadena intercavoaórtica a nivel del cuerpo de la segunda vértebra lumbar es el primer relevo de los nódulos linfáticos para el testículo derecho; los nódulos paraaórticos izquierdos están en el área limitada por la vena renal, la aorta, el uréter y la arteria mesentérica inferior, y son el primer relevo de los ganglios linfáticos para el testículo izquierdo; la extensión de forma cruzada es rara. El tumor dentro del epidídimo puede extenderse directamente a los ganglios iliacos externos. La extensión directa hacia los ganglios inguinales se observa en pacientes que tienen involucro de la piel $^{7-9}$. 
Algunos marcadores tumorales son importantes para el diagnóstico, la estadificación, el pronóstico y el seguimiento de los tumores de los células germinales. Muchos marcadores están bien identificados para su uso en las neoplasias testiculares, pero solo la alfafetoproteína y la subunidad beta de la hormona gonadotropina coriónica humana han demostrado utilidad clínica. La alfa-fetoproteína no se eleva en los seminomas puros y sí se encuentra elevada en tumores de células germinales mixtos con elementos del saco de Yolk. La subunidad beta de la hormona gonadotropina coriónica humana es un marcador de gran utilidad en los coriocarcinomas, ya que se eleva de forma importante por el gran número de células de sincitiotrofoblasto que contiene (Tabla 3).

Se han propuesto numerosas estadificaciones para los tumores testiculares malignos; en la práctica clínica, los pacientes son clasificados en bajo y alto grado. Los tumores de bajo grado se considera que están limitados al testículo, al epidídimo o al cordón espermático, y tienen pocas adenopatías. Los tumores de alto grado invaden la pared del escroto, y tienen adenopatías retroperitoneales y metástasis viscerales.

El US en escala de grises tiene una sensibilidad cercana al $100 \%$ para detectar tumores testiculares, pero su función principal es distinguir las masas intratesticulares de las extratesticulares. La mayoría de las neoplasias testiculares malignas son más hipoecogénicas que el parénquima testicular normal; sin embargo, la hemorragia, la necrosis, la calcificación y los cambios grasos pueden producir áreas de mayor o menor ecogenicidad dentro de los tumores.
El Doppler color y la angio-Doppler pueden demostrar un incremento de la vascularidad de los tumores malignos y ayudan a definir mejor el involucro testicular. Puede ser difícil demostrar el incremento de flujo sanguíneo en tumores pequeños $(<2 \mathrm{~cm})$; la presencia de hipervascularidad no es específica para un proceso de malignidad ${ }^{13-17}$.

\section{Planteamiento del problema}

¿Cuáles son los patrones ecográficas de los tumores testiculares de células germinales?

\section{Justificación}

El cáncer testicular es la neoplasia más común en hombres de 20 a 35 años de edad, afecta su mayor etapa productiva y reproductiva, el diagnóstico temprano tiene una tasa de curación del 99\% disminuyendo la morbimortalidad, y los tumores de células germinales representan el 90 al 95\% de todos los tumores, por lo que son la neoplasia más importante para su estudio y detección.

\section{Objetivo general}

Analizar las principales características ecográficas, clínicas e histopatológicas de los tumores testiculares de células germinales para un diagnóstico más temprano y preciso.

\section{Objetivos específicos}

Describir los patrones ecográficos que permitan sospechar la estirpe histopatológica, 
identificar el tipo y el subtipo de los tumores testiculares de células germinales más frecuentes en nuestro medio hospitalario, y revisar los principales síntomas de los pacientes con tumores testiculares de células germinales.

\section{MÉTODO}

Es un estudio transversal, descriptivo y retrospectivo. Se revisaron los registros del PACS (Picture Archive and Comunication System) para identificar pacientes referidos para US escrotal, en el periodo de enero de 2014 a noviembre de 2017. De manera simultánea se realizó una búsqueda del mismo periodo en la base de datos del servicio de anatomía patológica y se encontraron 21 pacientes con diagnóstico de tumores de células germinales, que también se encuentran en la lista de pacientes referidos para US. Se realizó la exploración ecográfica con dos equipos de US, utilizando transductores lineales multifrecuencia de $5 \mathrm{a} 17 \mathrm{MHz}$ y de 12 a $15 \mathrm{MHz}$, respectivamente, en escala de grises y con la aplicación de las modalidades Doppler color, Doppler pulsado, Doppler power (angioDoppler) y Doppler dúplex. Los hallazgos se clasificaron en neoplasias de células germinales de origen seminomatoso (clásico, espermatoquístico y anaplásico) o no seminomatoso (carcinoma de células embrionarias, tumor del saco vitelino o tumor del seno endodérmico, teratomas maduros e inmaduros, teratocarcinomas y coriocarcinomas), posterior al tratamiento quirúrgico y el estudio histopatológico.

\section{Criterios de inclusión}

- Estudios de US testicular realizados durante el periodo de enero de 2014 a diciembre 2017.
- Estudios completos, interpretados y comprobados por el servicio de anatomía patológica.

- Estudios realizados por el personal del área de US.

\section{Criterios de exclusión}

- Estudios incompletos, ya sea por la técnica, la interpretación o la comprobación por el servicio de anatomía patológica.

- Estudios realizados fuera del periodo de enero de 2014 a diciembre de 2017.

- Pacientes con patología inguinal.

- Estudios realizados por personal ajeno al servicio de US.

- Estudios que no se realizaron con los equipos de US ya descritos.

\section{RESULTADOS}

Se revisaron estudios de US testicular de 21 pacientes que presentaban diagnóstico de tumor testicular de células germinales confirmado por el servicio de patología. De ellos, se encontró que ligeramente por arriba de la mitad eran del tipo no seminomatoso (52\%) y el resto eran seminomatosos (48\%). Por subtipos histológicos, los más frecuentes son los seminomas clásicos (puros), en un $43 \%$, seguidos por los tumores de células germinales mixtos (19\%), los teratomas maduros (9\%), los carcinomas de células embrionarias (9\%), los tumores del seno endodérmico (5\%), los teratomas inmaduros 


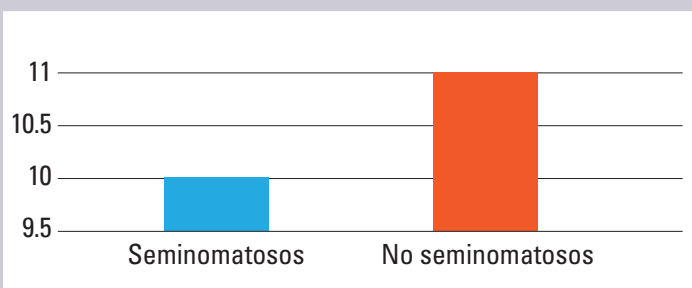

Figura 1. Distribución de los casos de tumores seminomatosos y no seminomatosos.

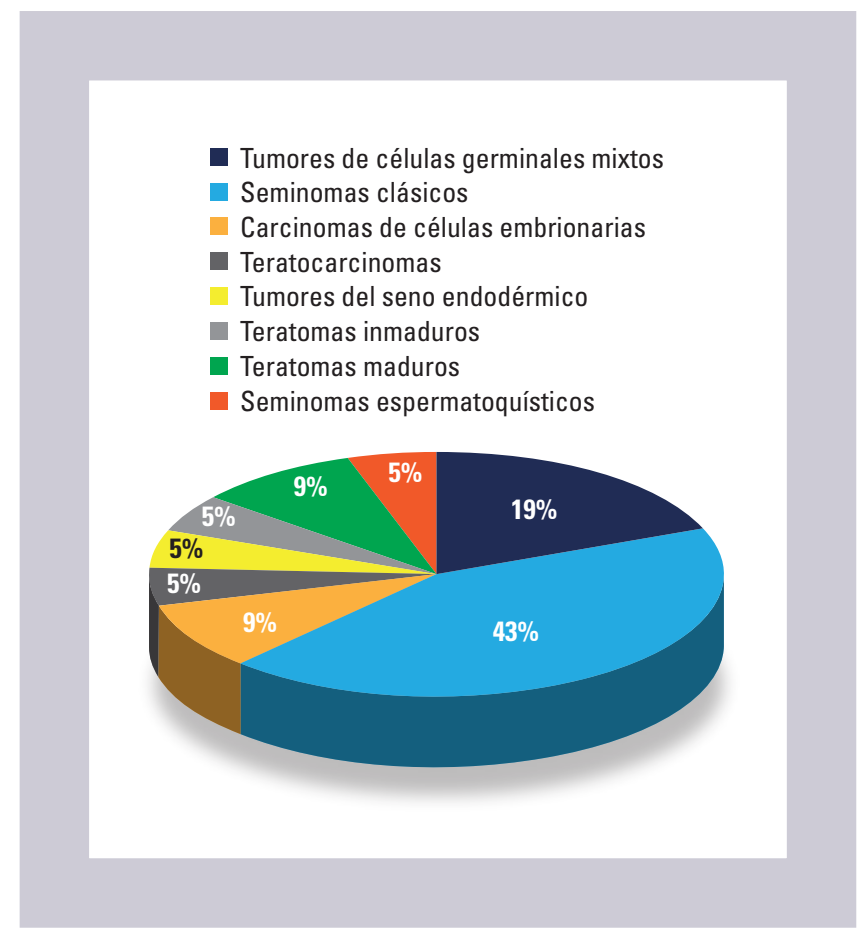

Figura 2. Representación del tipo histológico.

(5\%) y los seminomas espermatoquísticos (5\%); no hubo ningún caso de coriocarcinoma ni de seminoma anaplásico (Figs. 1 y 2).

La distribución de la edad de los pacientes en el estudio comprendió un rango entre los 15 y los 71 años, y la afección por tumores testiculares de células germinales fue principalmente en la cuarta (ocho casos) y la tercera (siete casos) décadas de la vida, con una media de edad de 34 años, de los cuales el 50\% estaba por encima de 31 años y el restante $50 \%$ estaba por debajo de esta edad (mediana: 31 años). La mayor frecuencia de afectación fue a los 28 años (moda: 28) (Fig. 3).

De acuerdo con los hallazgos de patología, poco más de la mitad (57\%) tuvo afectado el testículo izquierdo (Fig. 4).

Las lesiones fueron focales en su mayoría (20 de los 21 casos). Se identificó extensión locorregional neoplásica en 9 (48\%) pacientes, de los cuales 5 (24\%) tenían invasión vascular local, $3(14 \%)$ tenían invasión a la rete testis y $1(5 \%)$ hacia la túnica albugínea. Los diámetros de las lesiones fueron variables: la mayor de $10 \mathrm{~mm}$ y la menor de $1,7 \mathrm{~mm}$ (Figs. 5 a 8).

Se determinaron tres patrones ecográficos de acuerdo con sus características principales; de ellos, predominó el heterogéneo sólido $(67 \%)$, seguido del hipoecoico homogéneo en relación al parénquima testicular (28\%) $\mathrm{y}$, por último, el heterogéneo quístico $(5 \%)$. No se identificaron microcalcificaciones en 11 casos; de los que tuvieron microcalcificaciones, estas se dividieron en agrupadas (7 casos) y dispersas (3 casos). Casi todos estaban vascularizados (95\%). Más de la mitad (12 casos) presentaban bordes irregulares y en 9 casos se observaron bordes regulares (Figs. 9 a 12).

Los síntomas descritos son aumento de volumen testicular (9 casos), dolor leve (6 casos), induración (4 casos), varicocele (1 caso) y esterilidad (1 caso). Solo se documentó un paciente con metástasis a distancia (Fig. 13). 


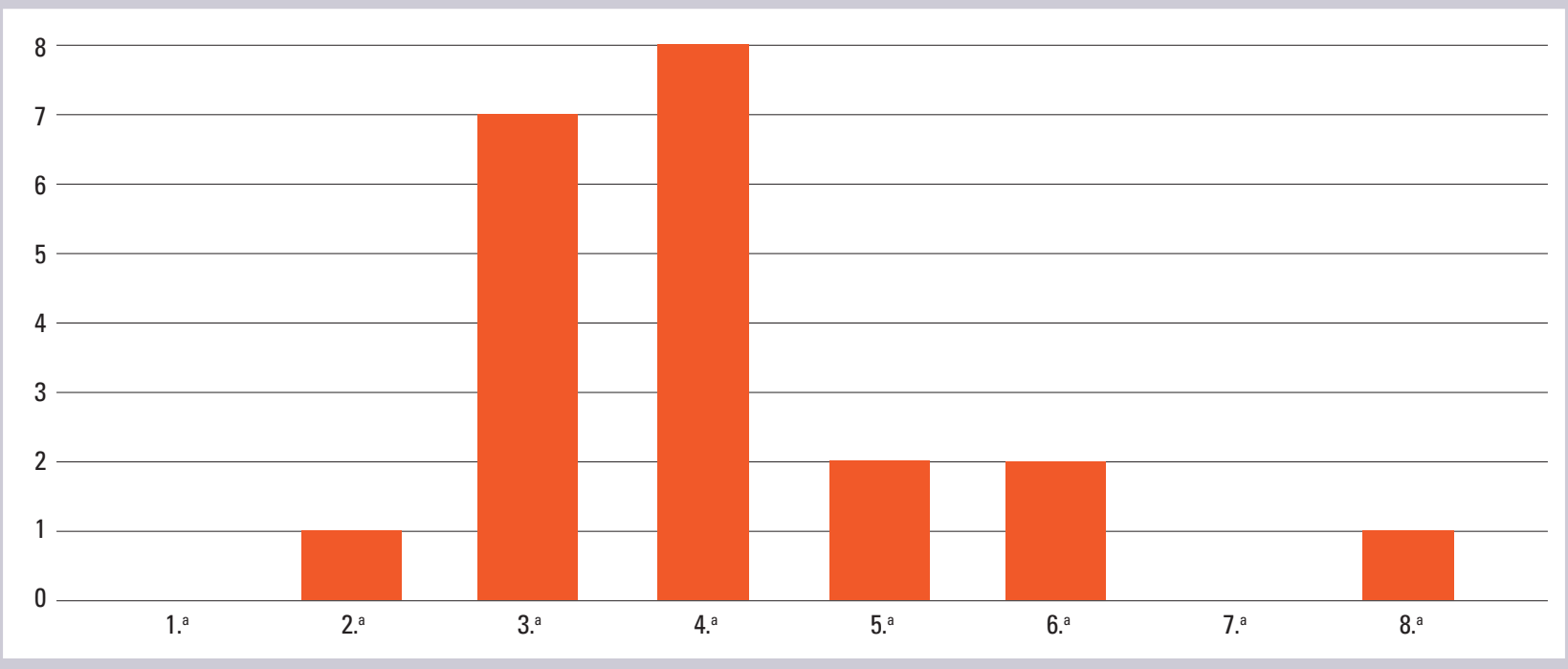

Figura 3. Distribución de acuerdo con la década de la vida.

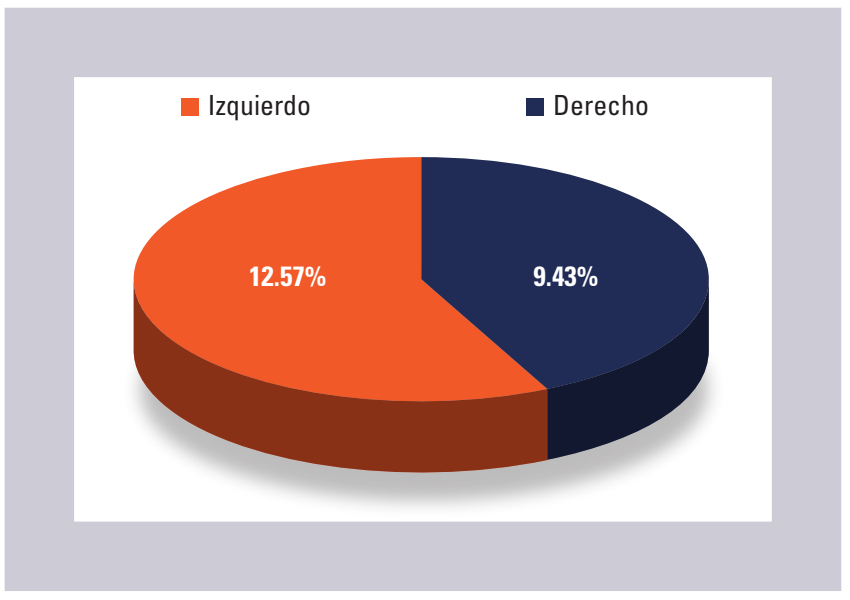

Figura 4. Distribución según el testículo afectado.

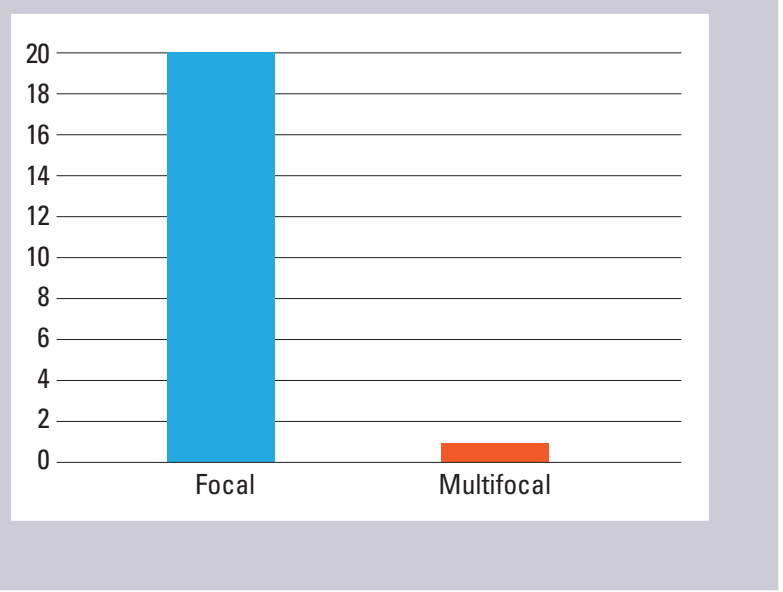

Figura 5. Distribución de las lesiones en el testículo por la imagen.

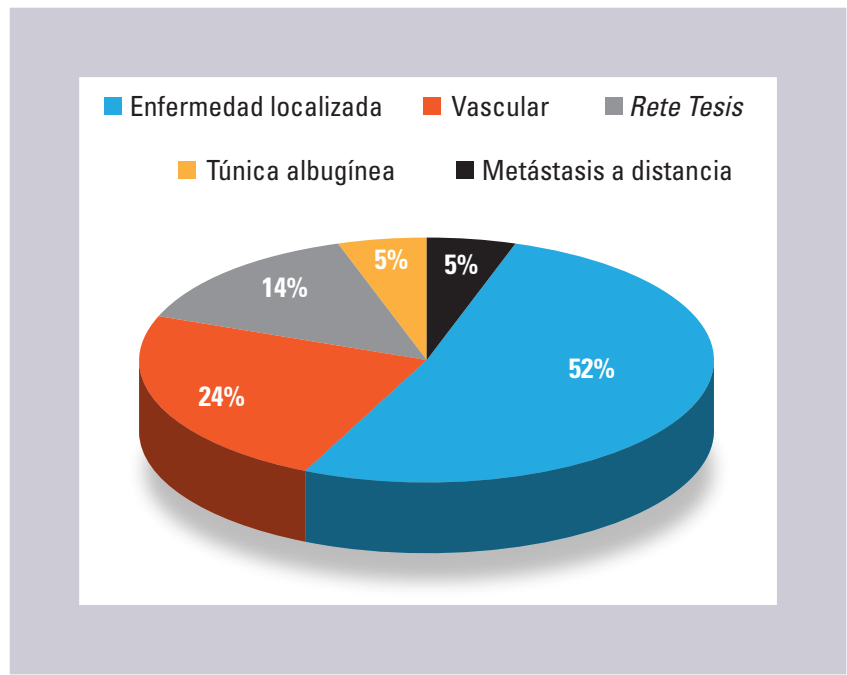

Figura 6. Distribución de la extensión de la invasión.

\section{DISCUSIÓN}

Los tumores de células germinales son la neoplasia testicular más frecuente. Los tumores de tipo no seminomatoso predominaron en nuestro estudio (52\%) con respecto a los seminomatosos, lo cual es relevante en el desarrollo natural de la enfermedad, en el pronóstico y en la respuesta al tratamiento. 


\section{Anales de Radiología México. 2018;17}

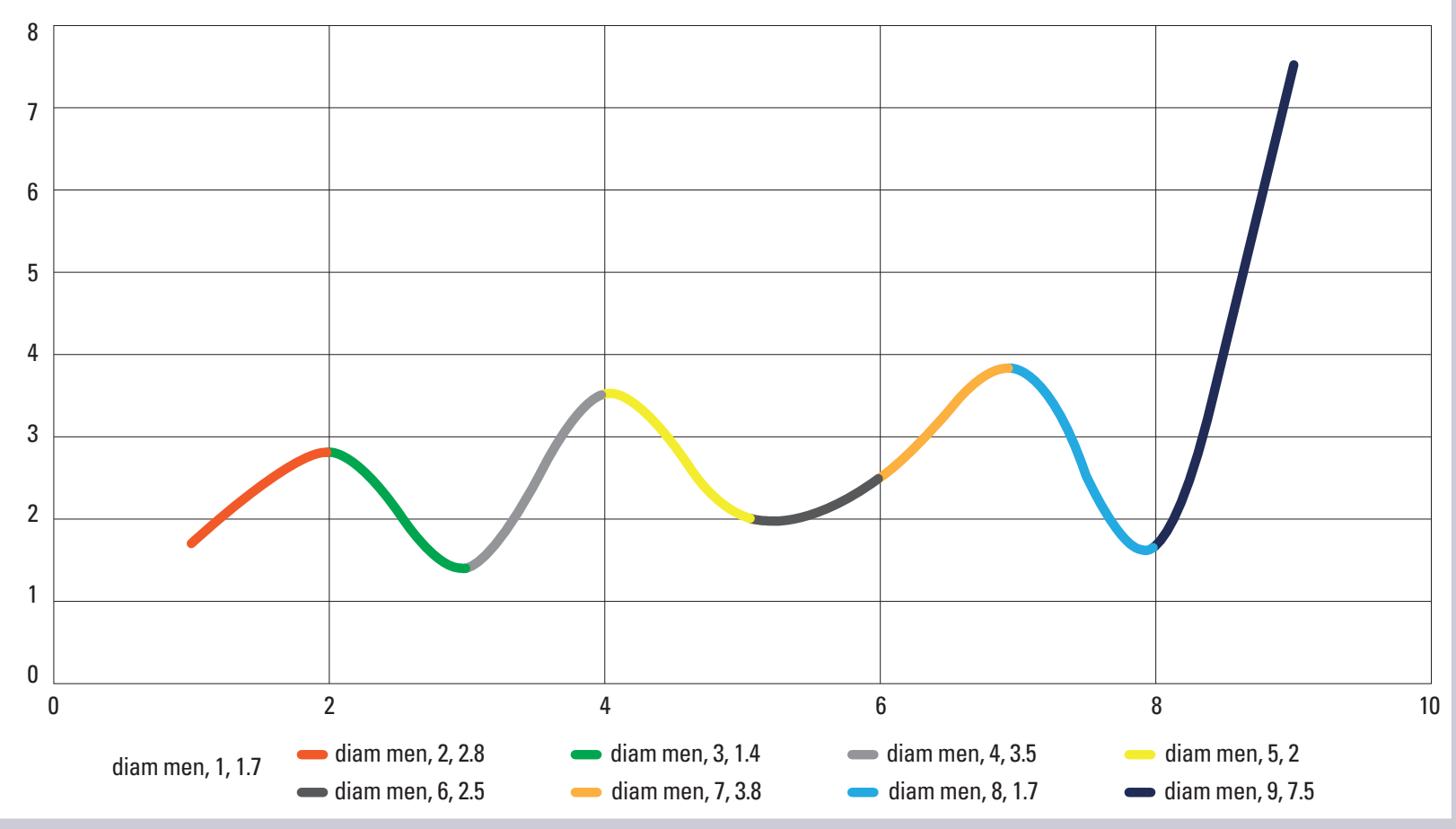

Figura 7. Distribución del diámetro menor (diam men), en milímetros.

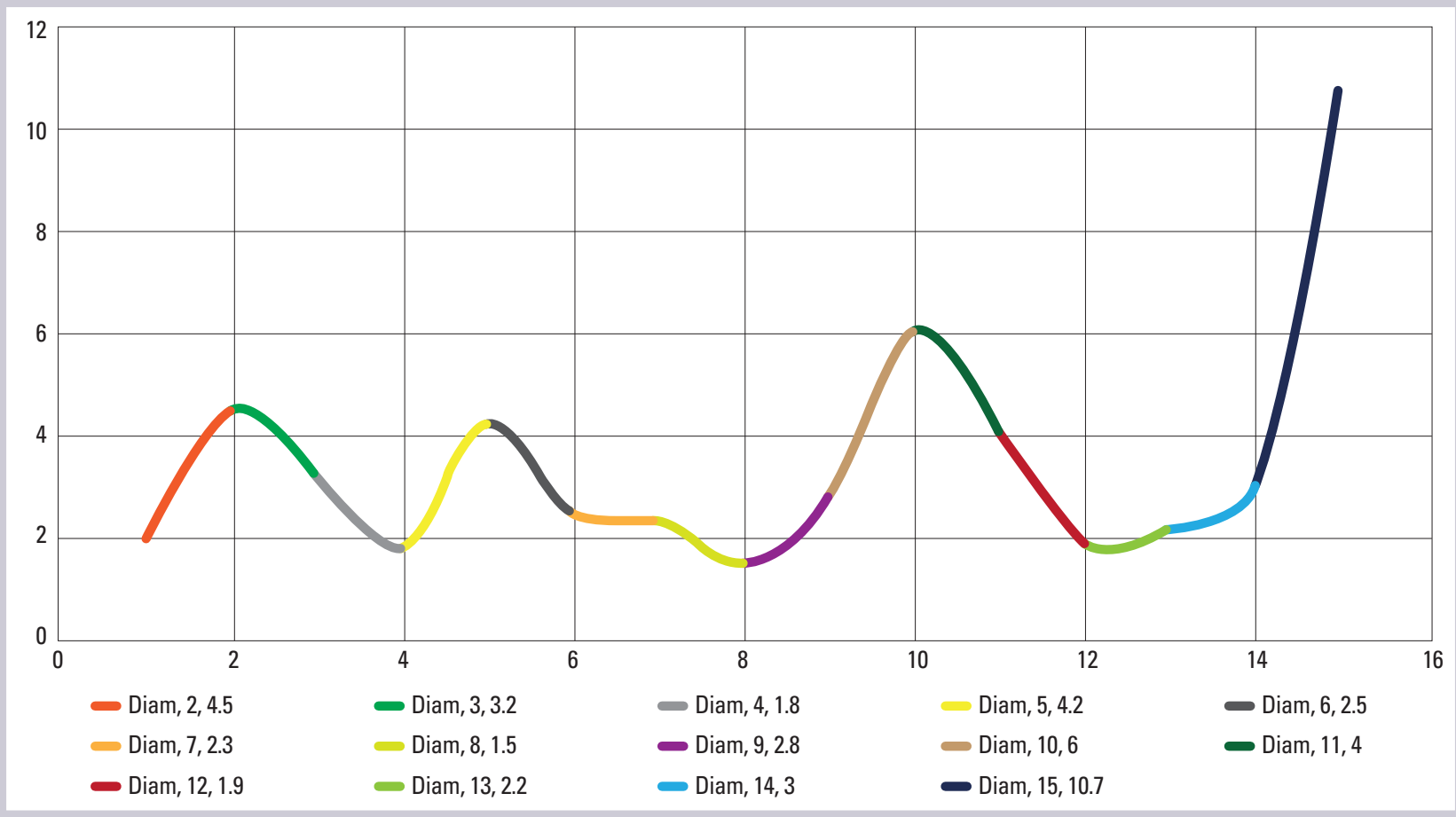

Figura 8. Distribución del diámetro mayor (Diam), en milímetros. 


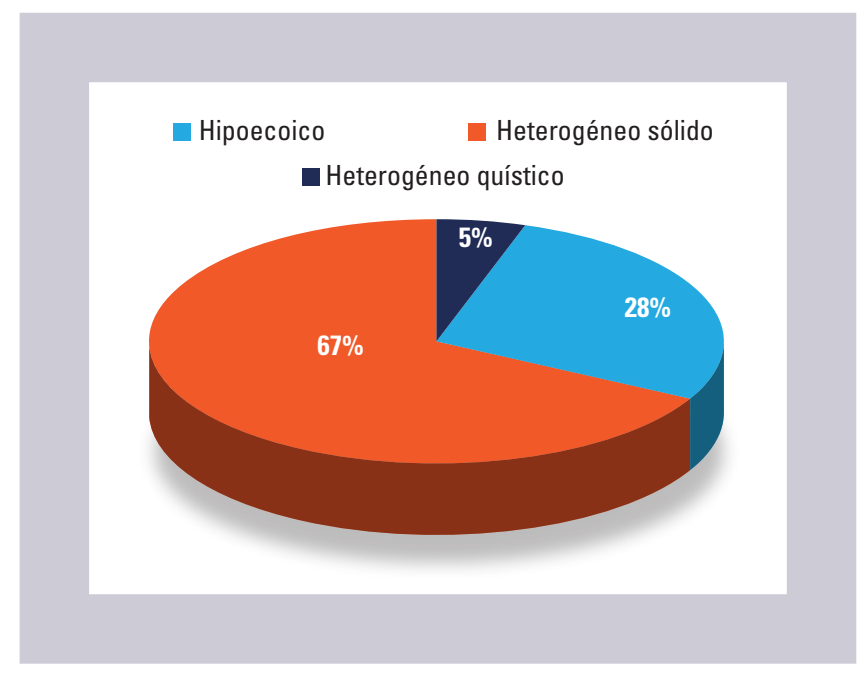

Figura 9. Patrón ecográfico de los tumores testiculares de células germinales.

Entre los subtipos, el de mayor frecuencia es el seminoma clásico (puro), seguido por los teratomas de células germinales mixtos; esto también es muy similar a lo descrito en la literatura. Es importante mencionar que se presentó un solo caso de seminoma espermatoquístico en un paciente de 50 años como variante muy poco frecuente; además, hubo un caso de metástasis secundarias a un teratoma maduro.

La frecuencia por grupo de edad fue mayor en la tercera y la cuarta décadas de la vida, pero hubo casos en los extremos de edad, en pacientes de 15 y 71 años, respectivamente.

Los tumores de células germinales se presentan con más frecuencia como una lesión focal; la multifocalidad se observó en un solo caso, que a su vez presentó extensión de la invasión vascular local, por lo que dicha multifocalidad no se considera determinante para la extensión. La extensión vascular a la rete testis y a la túnica albugínea no se logra determinar con exactitud en el US, pero la mayoría de estas lesiones son de mayor tamaño que las no invasivas, por lo que se infiere que a mayor volumen tumoral hay un mayor involucro locorregional. La afectación de predominio izquierdo aparentemente es poco significativa, ya que en el lado derecho fue casi similar.

La determinación de los patrones ecográficos con predominio del heterogéneo sólido lo hace sugestivo de tumor testicular sin una estirpe histológica específica; el patrón ecográfico hipoecoico homogéneo está presente principalmente en los tumores seminomatosos, aunque algunos de ellos también se presentaron como heterogéneos de predominio sólido. El último patrón ecográfico, heterogéneo de predominio quístico, se relacionó con mayor extensión de la invasión del tumor, como en el caso del único paciente con metástasis a distancia, probablemente por el rápido crecimiento del tumor, ocasionando áreas de necrosis y formaciones quísticas (Figs. 14 a 17).

Los bordes no representan una característica determinante en cuanto a la invasividad, ya que varios casos con bordes regulares tuvieron extensión locorregional (Fig. 18). Sin embargo, es importante destacar que casi todos (95\%) los tumores estaban vascularizados, característica ecográfica que puede ayudar a distinguirlos por imagen de otras lesiones no neoplásicas (Fig. 19). Las microcalcificaciones se observaron en un $52 \%$ de los casos (Fig. 20).

De los pacientes estudiados, nueve refirieron la percepción de aumento de volumen testicular en exploraciones fortuitas; otro grupo 


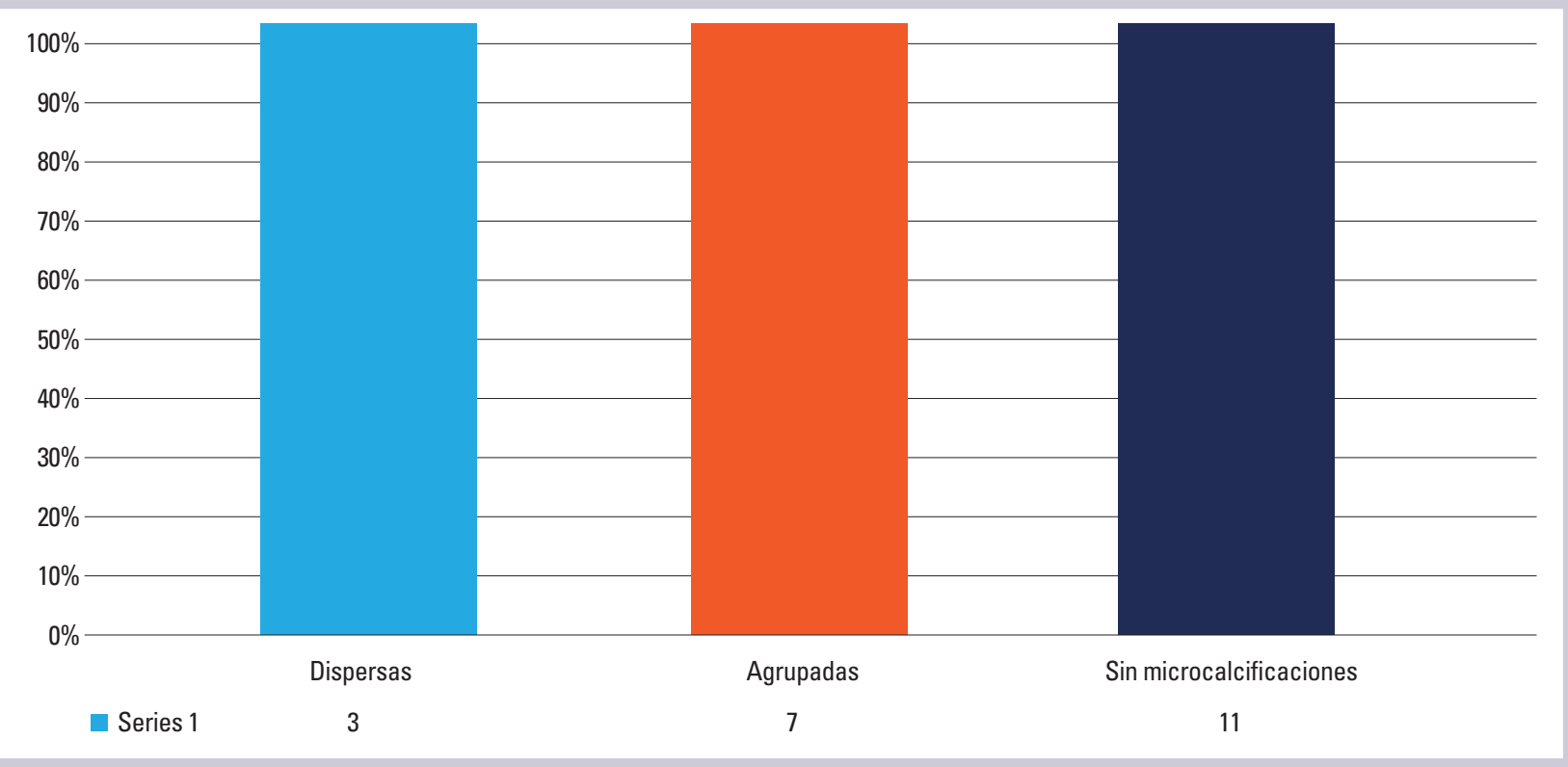

Figura 10. Distribución de las calcificaciones en el parénquima testicular.

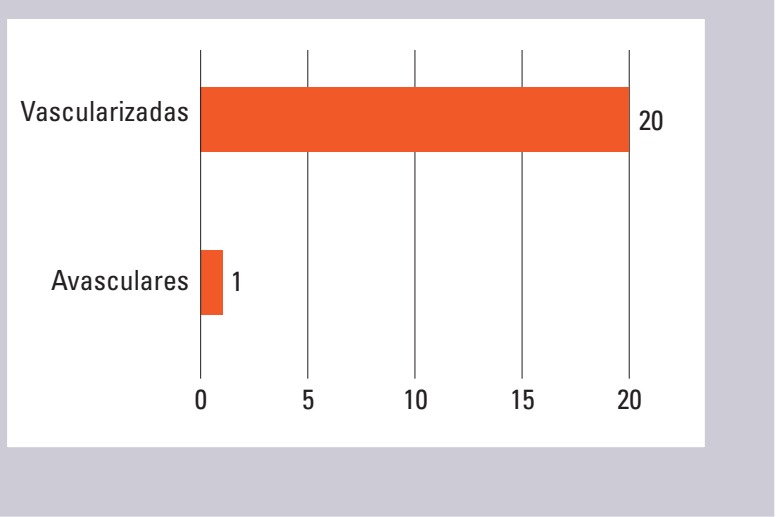

Figura 11. Valoración del flujo vascular en las lesiones con la aplicación de Doppler color y de Doppler power.

ligeramente menor de seis casos refirió dolor leve de varios días a semanas de evolución; los otros pacientes que percibieron induración solo fueron cuatro, y lo hicieron después de una exploración no intencionada; en los otros dos fue por hallazgos ecográficos incidentales (uno acudió para descartar un varicocele y el otro se encontraba en protocolo de estudio por infertilidad).

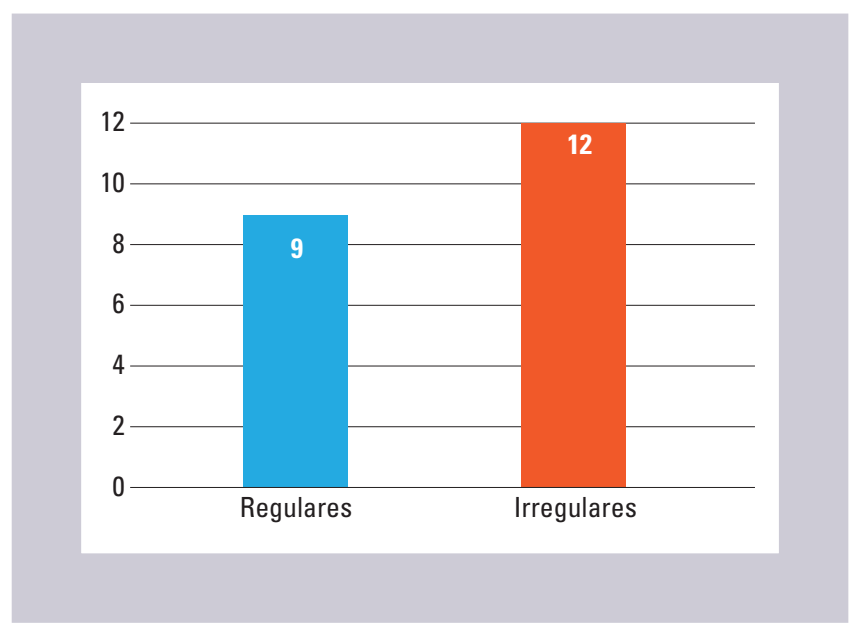

Figura 12. Caracterización de los bordes de las lesiones.

\section{CONCLUSIÓN}

En el presente trabajo corroboramos la utilidad y como estudio de elección del US en la valoración de tumores testiculares de células germinales, que además tiene la ventajas de su bajo coste, fácil realización, ausencia de radiación ionizante, gran disponibilidad respecto a otros métodos de imagen y buena calidad de imagen. 


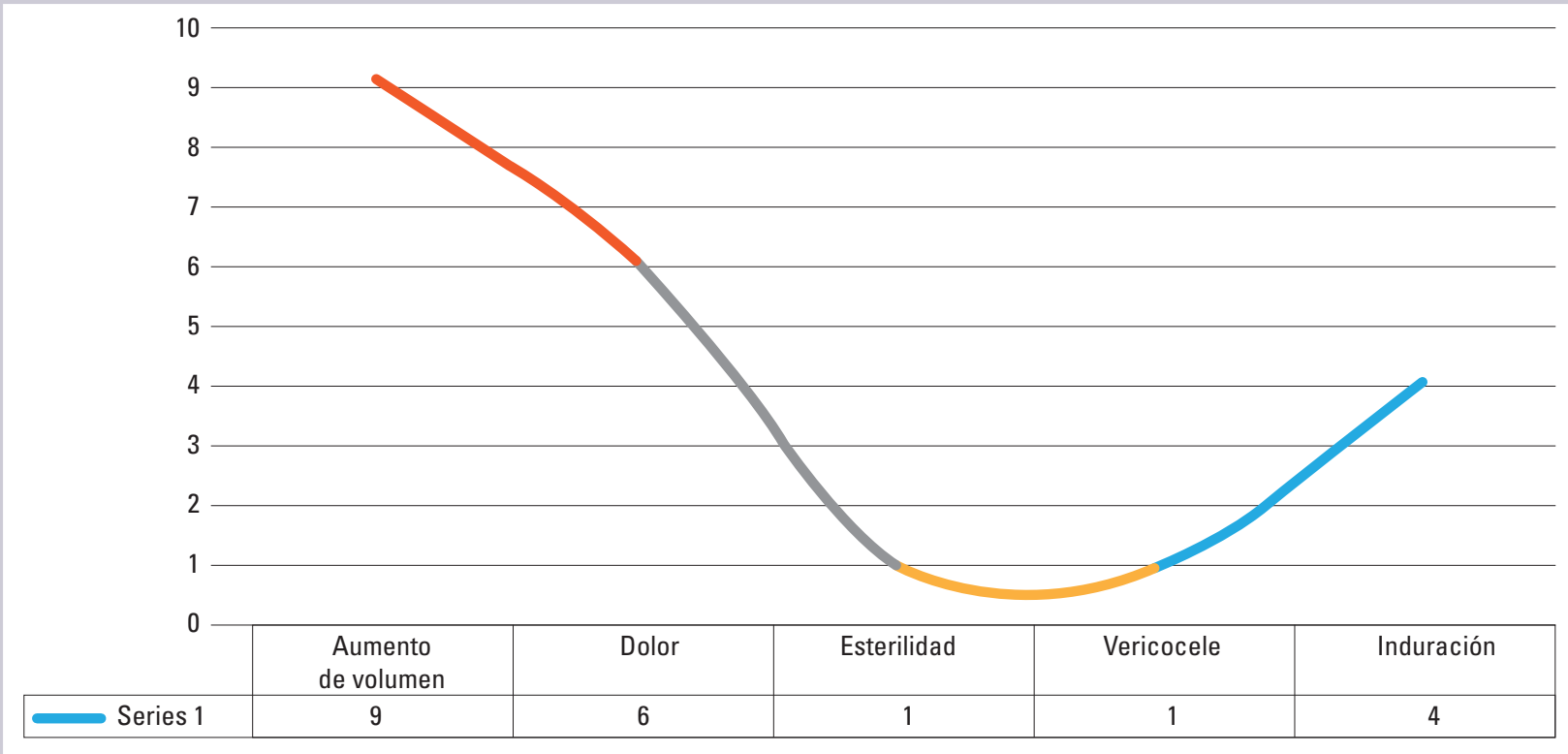

Figura 13. Presentación clínica de los tumores testiculares de células germinales.

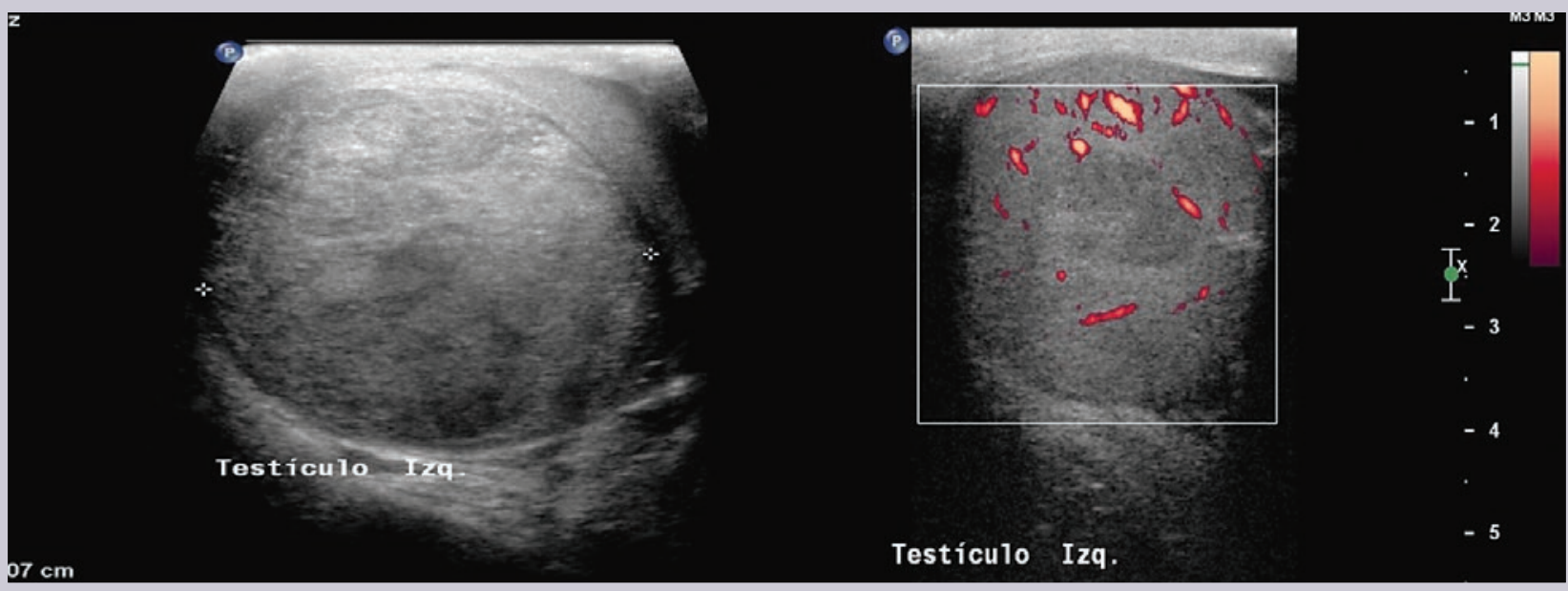

Figura 14. Patrón ecográfico heterogéneo sólido. Ultrasonido testicular en proyecciones transversales en escala de grises y angioDoppler que muestran un seminoma clásico.

Sin embargo, para valorar la extensión de la enfermedad testicular neoplásica se necesita la realización de estudios adicionales que tienen una mejor resolución espacial y ayudan a una estadificación más precisa, como la tomografía, la resonancia magnética y la tomografía por emisión de positrones.
De acuerdo con los resultados de nuestro estudio, sugerimos la realización de estudios de cribado con US en los pacientes con factores de riesgo. Las manifestaciones clínicas que podrían ayudar a la sospecha son el aumento de volumen escrotal y el dolor leve, que son síntomas de mayor cronicidad. 


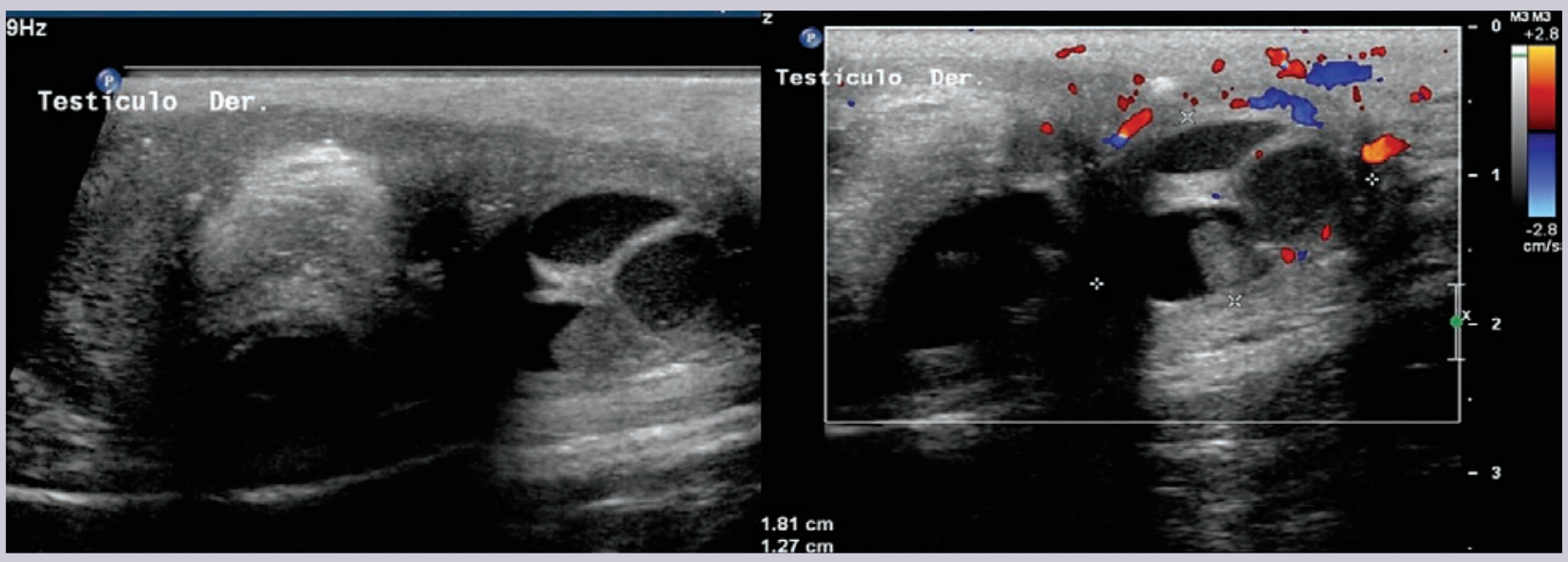

Figura 15. Patrón ecográfico heterogéneo de predominio quístico. Ultrasonido testicular en proyecciones longitudinales en escala de grises y Doppler color que muestran un teratoma maduro.

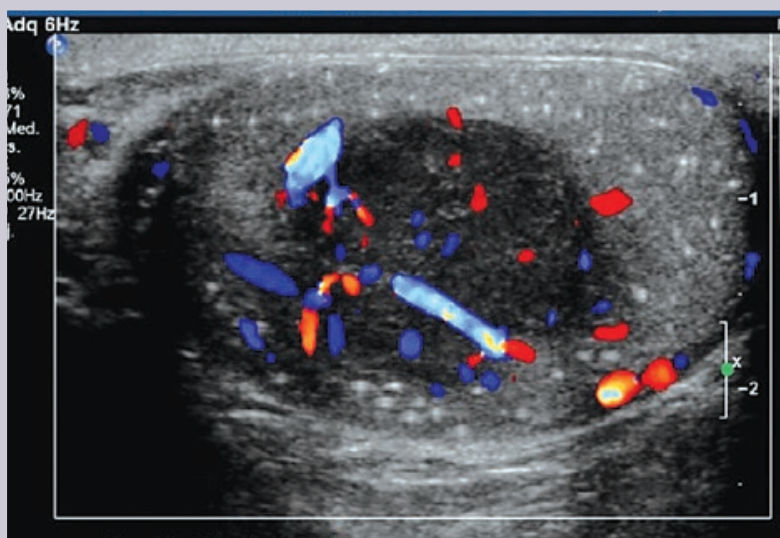

Testículo Der.

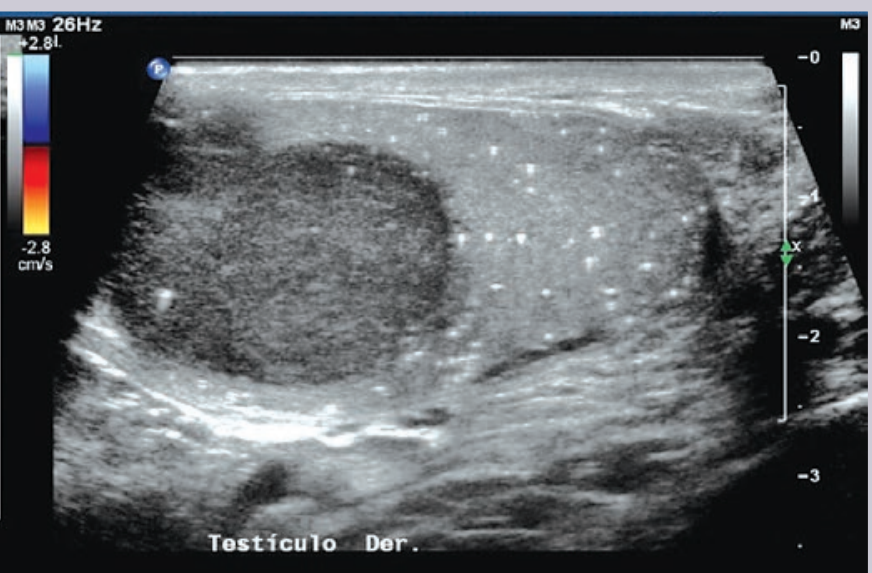

Figura 16. Patrón hipoecogénico con respecto al resto del parénquima testicular. Ultrasonido testicular en proyecciones transversal y longitudinal, en escala de grises y con Doppler color, que muestran un seminoma clásico.

En comparación con otras enfermedades no neoplásicas, es importante referir que la extensión de la invasión fue ligeramente mayor en aquellos que no tenían clínica de patología testicular.

Se observó un discreto predominio de los tumores no seminomatosos respecto a los seminomatosos, lo cual es importante para el pronóstico y la respuesta al tratamiento, lo que también nos exige hacer una amplia, detallada e intencionada revisión de la extensión de la invasión que más comúnmente se produce en estos tumores, ya que de forma general los tumores no seminomatosos tienen un comportamiento más agresivo.

El patrón ecográfico no es especifico de un tipo o subtipo, y ello nos evita asignar de 


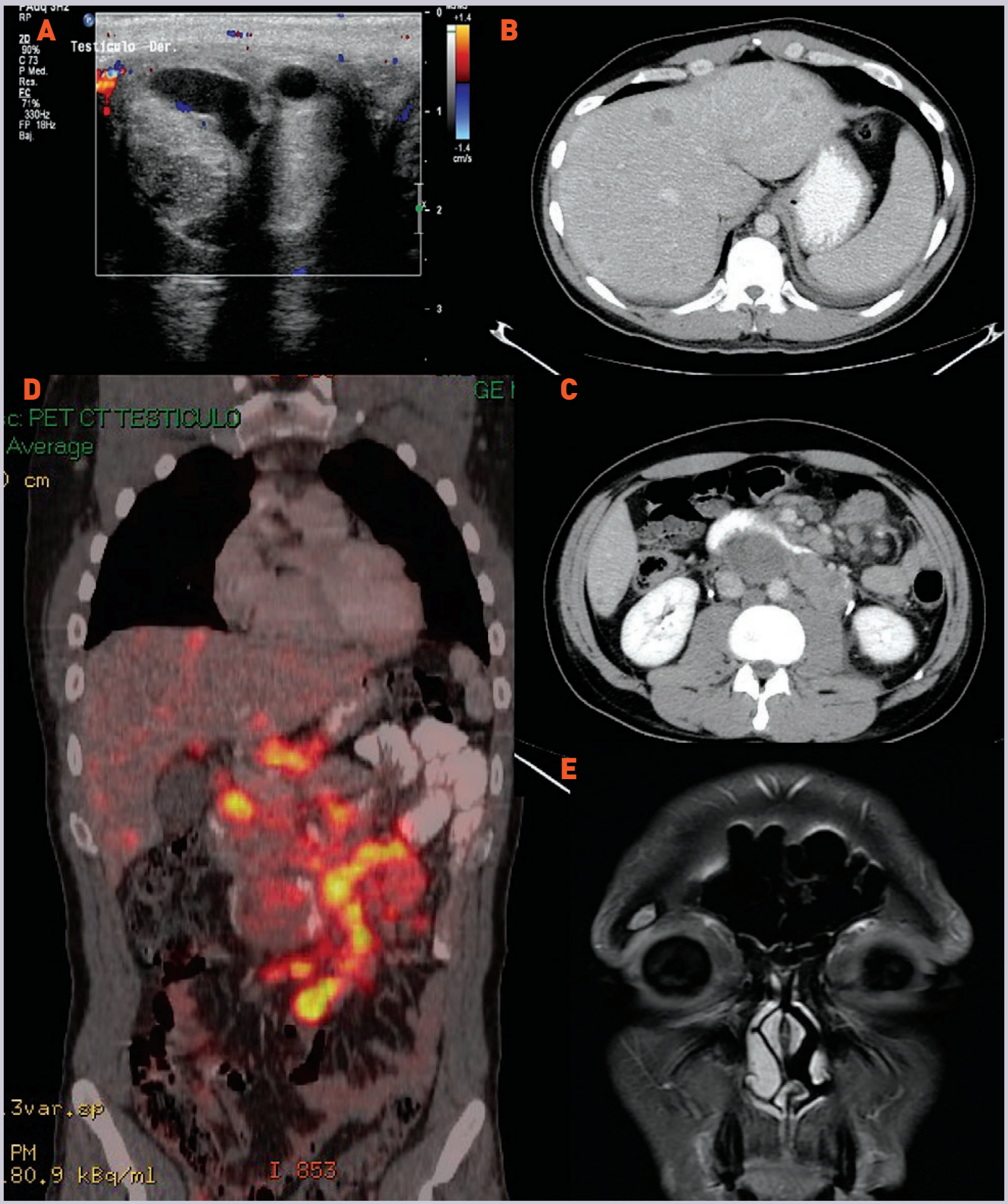

Figura 17. Paciente con metástasis a distancia. A: ultrasonido testicular que muestra una neoplasia heterogénea de predominio quístico (teratoma maduro). B y C: tomografía computarizada con medio de contraste oral e intravenoso en la que se aprecian metástasis en el hígado y adenopatías retroperitoneales. D: tomografía por emisión de positrones con captación de la fluorodesoxiglucosa por los ganglios retroperitoneales. E: resonancia magnética en secuencia T1 con gadolinio; imagen supraorbitaria correspondiente a metástasis. 


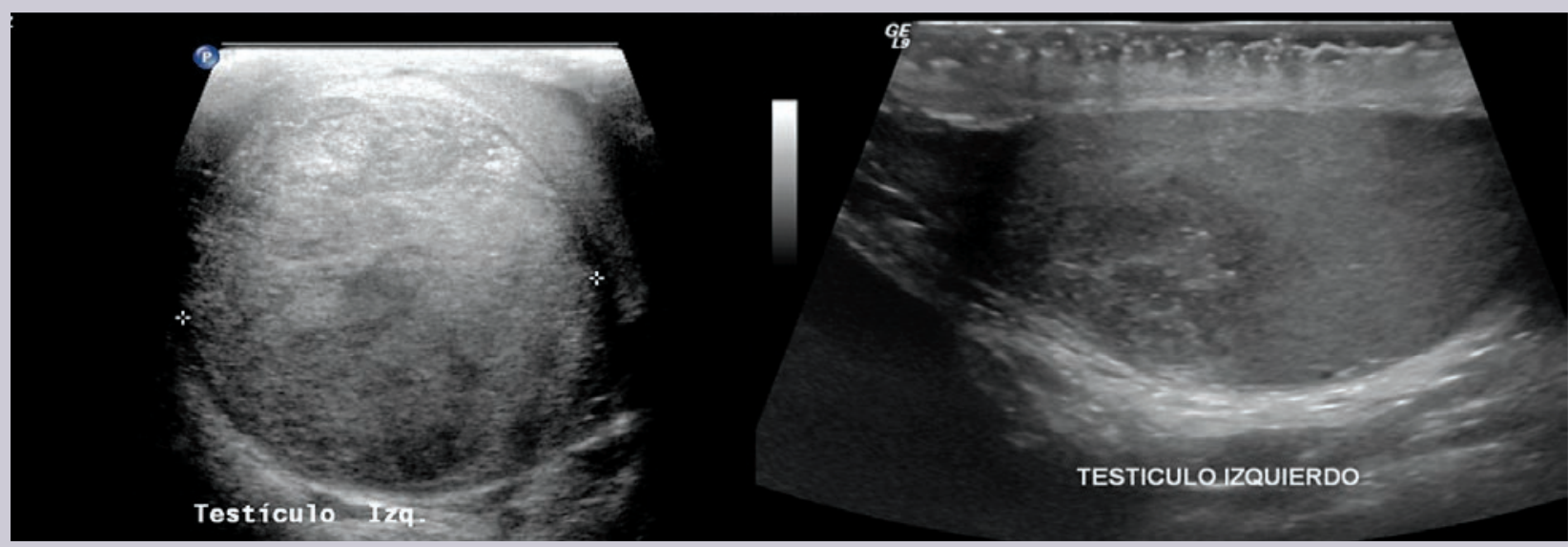

Figura 18. Patrón de bordes regulares e irregulares. Ultrasonido testicular en proyecciones transversal y longitudinal, en escala de grises, que muestra un seminoma y un carcinoma embrionario.

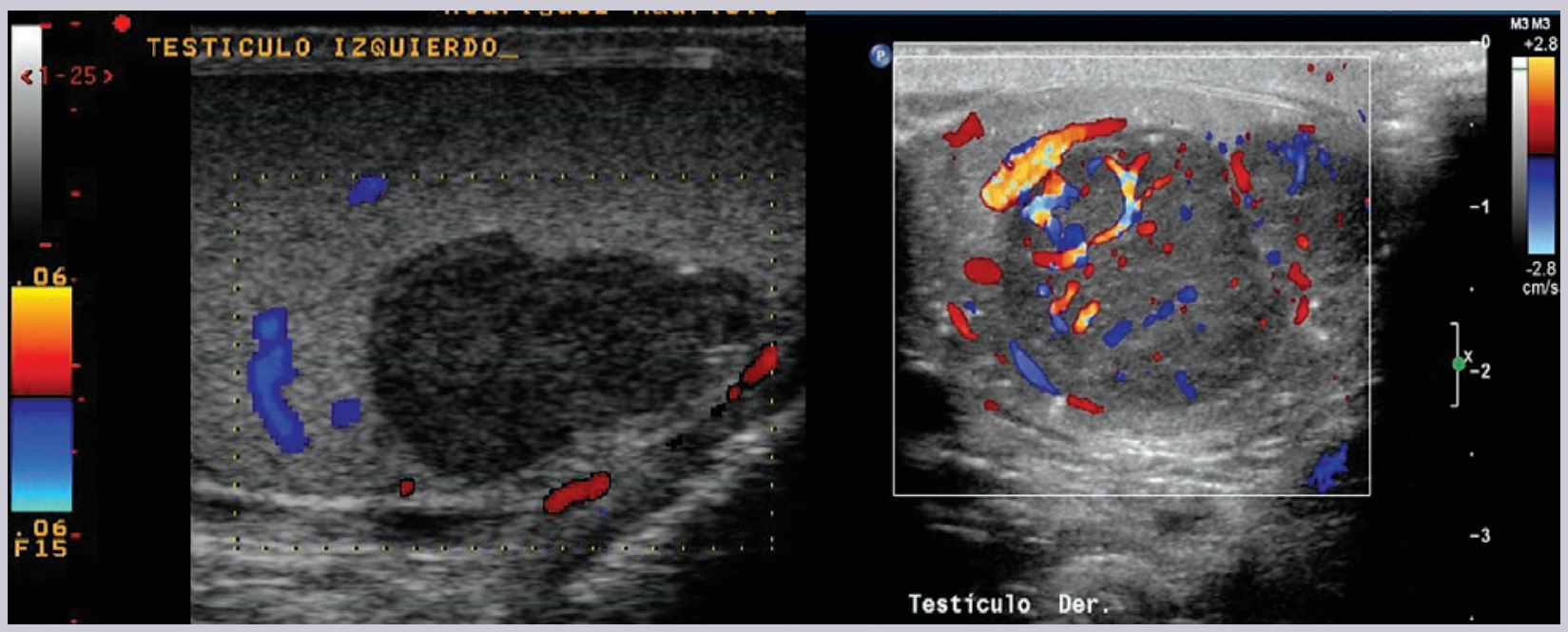

Figura 19. Patrón hipovascular e hipervascular. Ultrasonido testicular en proyecciones, con aplicación de Doppler Color, que muestra seminomas avascular e hipervascularizado.

forma errónea un diagnóstico impreciso y probablemente limitado por US. Sin embargo, sí es importante mencionar que la presentación de un patrón ecográfico heterogéneo de predominio quístico se correlacionó con una mayor extensión de la invasión por su rápido crecimiento. La mayoría de los seminomas tienen un patrón hipoecogénico homogéneo, pero no es específico del mismo subtipo tumoral, como hemos dicho.

La aplicación de las modalidades de Doppler color y Doppler power (angio-Doppler) es un requisito de toda exploración ultrasonográfica testicular, ya que los tumores muestran un aumento de la vascularidad que permite 


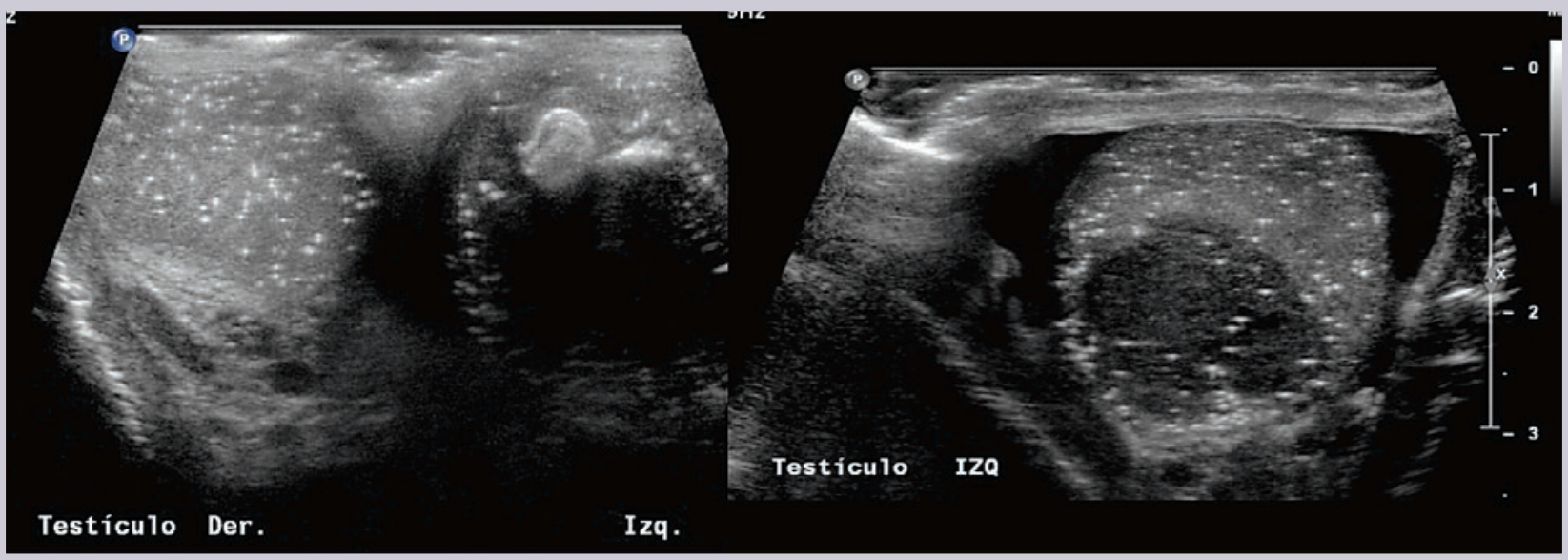

Figura 20. Patrón de distribución de las microcalcificaciones. Ultrasonido testicular en proyecciones transversales en escala de grises en el que se aprecian microcalcificaciones agrupadas y dispersas, así como teratoma maduro y seminoma.

diferenciarlos de otras lesiones. Es menester dar seguimiento a las microcalcificaciones agrupadas, ya que en varios casos se relacionaron con lesiones tumorales, aunque no está demostrado. Por último, es de igual manera importante mencionar que los bordes regulares no implican limitación del tumor. El presente estudio es limitado por el número de pacientes, pero podría ser la base de estudios más extensos.

\section{RESPONSABILIDADES ÉTICAS}

Protección de personas y animales. Los autores declaran que para esta investigación no se han realizado experimentos en seres humanos ni en animales.

Confidencialidad de los datos. Los autores declaran que en este artículo no aparecen datos de pacientes.

\section{Derecho a la privacidad y consentimiento} informado. Los autores declaran que en este artículo no aparecen datos de pacientes.

\section{BIBLIOGRAFÍA}

1. Gospodarowicz M. Testicular cancer patients: considerations in long-term follow-up. Hematol Oncol Clin N Am. 2008;22:245-55.

2. Shaw J. Diagnosis and treatment of testicular cancer. Am Fam Physician. 2008;77:475-6.

3. Rumack CM, Wilson SR, Charboneau WJ. Diagnóstico por ecografía. 2. ${ }^{a}$ ed. Madrid: Marban; 2005. p. 791-821.

4. Sadler TW, Leland J. Embriología médica con orientación clínica. 9.a ed. Baltimore y Philadelphia. Panamericana. p. 355-60.

5. Aso C, Enríquez G, Fité M, Tóran N, Piqueras J, Lucaya J. Gray-scale and color Doppler sonography of scrotal disorders in children: an update. Radiographics. 2005;25:1197-214

6. De Giorgi U, Pedrazzoli P, Rosti G; Italian Germ-Cell Cancer Group; Gruppo Italiano per il Trapianto di Midollo Osseo, Cellule Staminali Emopoietiche e Terapia Cellulare. Testicular germ-cell cancer. N Engl J Med. 1997;337:242-53.

7. Kocakoc E, Bhatt S, Dogra VS. Ultrasound evaluation of testicular neoplasms. Ultrasound Clin. 2007;2:27-44.

8. Kim W, Rosen MA, Langer JE, Banner MP, Siegelman ES, Ramchandani P. US-MR imaging correlation in pathologic conditions of the scrotum. Radiographics. 2007;27:1239-53.

9. Federle MP. Diagnostic imaging abdomen. 3rd ed. Salt Lake City, Utah. AMIRSYS; 2008. p. III,6,14-29.

10. Shaaban AM, Blodgett TM, Rezvani M, Heilbrun M, Salam ME, Roberts CC, et al. Diagnostic imaging oncology. Canada. AMIRSYS; 2011. p. 114-31.

11. Coley BD. The acute pediatric scrotum. Ultrasound Clin. 2006;1:485-96.

12. Dogra V, Gottlieb RH. Sonography of the scrotum. Radiology. 2003;227:18-36.

13. Ahmet $\mathrm{T}$, Bhatt $\mathrm{S}$, Dogra V. Acute painful scrotum. Ultrasound Clin. 2008;3:93-107.

14. Middleton WD, Teefey SA, Santillan CS. Testicular microlithiasis: prospective analysis of prevalence and associated tumor. Radiology. 2002;224:425-8.

15. Bushby LH. Scrotal calcification: ultrasound appearances, distribution and etiology. Br J Radiol. 2002;75:283-8.

16. Middleton WD. Testicular microlithiasis: prospective analysis of prevalence and associated tumor. Radiology. 2002;224:425-8.

17. Karellas ME, Damjanov I, Holzbeierlein JM. ITGCN of the testis, contralateral testicular biopsy and bilateral testicular cancer. Urol Clin North Am. 2007;34:119-25 